\title{
Article
}

\section{Failure to care: Nursing in a state of liquid modernity?}

\author{
Randall, Duncan and McKeown, Mick \\ Available at http://clok.uclan.ac.uk/11943/ \\ Randall, Duncan and McKeown, Mick ORCID: 0000-0003-0235-1923 (2014) \\ Failure to care: Nursing in a state of liquid modernity? Journal of Clinical \\ Nursing, 23 (5-6). pp. 766-767.
}

It is advisable to refer to the publisher's version if you intend to cite from the work. http://dx.doi.org/10.1111/jocn.12441

For more information about UCLan's research in this area go to http://www.uclan.ac.uk/researchgroups/ and search for < name of research Group>.

For information about Research generally at UCLan please go to http://www.uclan.ac.uk/research/

All outputs in CLoK are protected by Intellectual Property Rights law, including Copyright law. Copyright, IPR and Moral Rights for the works on this site are retained by the individual authors and/or other copyright owners. Terms and conditions for use of this material are defined in the policies page.

\section{CLoK}

Central Lancashire online Knowledge www.clok.uclan.ac.uk

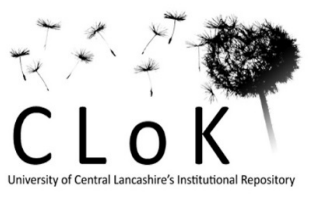




\section{Failure to care: Nursing in a state of liquid modernity?}

Dr Duncan Randall, University of Birmingham

Dr Mick McKeown, University of Central Lancashire

There has been significant public interest recently concerning perceived inadequacies in the quality of nursing care. Across a number of settings there has been a litany of neglect and abuse leading to both accusations of a compassion deficit and counter-claims from nurses and nursing scholars. While some of what we are seeing in the media is moral panic and reporting exceptional cases there has been an increase in complaints made about nurses in several countries (e.g. HM Government 2013). The number of media stories on the systematic failure of nurses to provide care would seem to indicate at least some level of a problem over and above media hyper attention.

We know what makes good nursing and good nurses: nursing is perhaps one of the most highly regulated professions with national and internationally stated criteria for practice and education. Even children know what makes a good nurse (Randall \& Hill 2012). We have had countless leadership programmes and health improvement programmes and yet we see now the failure of nurses, their leaders and of organizations to put in place safeguards that provide patients and nurses with cultures that consistently deliver safe human care. Why?

What we want to argue is that this failure of caring systems is directly related to the liquidification of nursing. Zygmunt Bauman (2000) describes a state of liquid modernity, a phase in the development of capitalism where uncertainty reigns and stability is forever undermined. Without wishing to idealise a supposed "golden age", arguably, in the 1950's nursing was more "solid". The matron ruled, nurses were educated in hospitals to which they were expected to owe a debt of gratitude and to work in the same hospital upon qualification. There was a sense that one worked one's way up through a perhaps rigid somewhat militaristic structure of staff nurse, junior sister, sister, senior sister, matron. This solid system had certainty about it, but also nurses were encouraged and rewarded for staying in one place; working for the hospital in which they had trained. Patients too were 
expected to be in hospital for longer periods. Bauman argues that this solidity and sense of location allows systems to be human. It is worth investing in relationships if you can anticipated a certain longevity within which social ties may strengthen and deepen; or if you think you are going to be around if people come back to complain! For nurses it is worth investing time and effort in getting to know patients and their families as people if you are going to be working in a community over time.

Contrast this with the liquidification, routinisation and application of technology to nursing of more recent times. Now nurses are educated by universities in various hospitals, they are encouraged to seek employment on the "open market". Despite attempts to structure nursing careers (DH 2006) it remains unclear what is required of nurses to progress to clinical nurse specialist or nurse consultant levels. Patterns of promotion, even at the initial clinical levels, vary between employers. There is a much faster turnover of staff, and of patients too. Many of the important functions of the nurse are being mechanised often in a bid for alleged quality improvement. The nurses' role is atomised and restructured as a set of competencies or colour coded tick-box forms which arguably could be completed by any suitably trained person. Thus the liquid state is one of fast moving uncertainty and ambivalence, where it is difficult to establish and maintain relationships. Fear stalks the workforce; the liquid-state fear of being replaced, moved or removed. In the UK it is claimed that the NHS lost over 6,000 nursing posts between 2010 and 2012. Although the actual number of nurses who are reorganised or made redundant may be relatively small, that is not the point; it is the fear of being reorganised or replaced which dominates and pervades nurses' thinking. This leads nurses to disinvestment in caring for people as fellow human beings.

For Bauman, contemporary society finds itself in a perpetual condition of uncertainty. Attempts to design order into systems, such as healthcare systems, are actually doomed to precipitate unanticipated obstacles and problems, ultimately leading to disorder. In some sense, Bauman is concerned with the potential for realising forms of human autonomy and solidarity, but sees this frustrated by the advancement of a consumerist culture as a characteristic of late capitalism. As such, there is a degree of resonance with earlier writing which explored the alienating effects of workplace technologies or the emotional labour of 
public service jobs (Hochschild, 1983), and these ideas have been applied to better understand nursing roles and experiences (Theodosius 2008). Alienation in nursing work is both similar to that experienced by other workers, stemming from lack of control over ones work and how it is organised, but may also involve some factors fairly unique to nursing, such as dealing intimately with the body in illness which may be beyond the control of the nurse or healthcare more generally. The application of technologies to health care practices mirrors the routinisation and degradation of work experienced in production line technologies and threatens the notion of nursing as a craft or the potential for flexible specialisation, wherein skilled practitioners strive to maintain control over all aspects of the nursing process.

Alternately, Reich (2012) describes the frustrations which come from valuing a capacity to utilise positive emotions in the delivery of care but having this undermined by, for example, a poverty of resources, lack of time or unsupportive management driven by contradictory ideology. He contrasts this martyred heart with Hochschild's managed heart. For authors like Reich, mainly concerned with nursing's industrial relations, collective union organising offers one route for redemption: the mobilised heart.

Trade unions, however, face their own modernity problems, not least a crisis of legitimacy. Ideally, union renewal tactics that emphasise relationships within and without the workplace (for healthcare workers, perhaps involving alliances with service user groups) might be part of a re-energising and re-legitimation project with as yet unpredictable ends (McKeown et al. in press). In the nursing context, uncertainty over the legitimacy of unions is exacerbated by current low levels of membership and union density in some work places, though the capacity for nursing unions to exert their power is often underestimated (Briskin 2011).

Ultimately, the pursuance of an enfranchised voice for nurses through organising and participation strategies opens the door to consider new models of workplace relations that privilege democratic decision making. For nursing this could be a new dawn, opening the door to more cooperative and collaborative workplace relations with colleagues and patients; possibly escaping alienation and reasserting some stability to counteract the 
tendency for liquidification. Indeed, the very social conditions upon which liquid modernity is predicated also allow for the spontaneous emergence of new social movements to resist injustice and inequities, and radical disability and service user/survivor groups are one interesting example of this. For Bauman, uncertainty in social relations is matched by shifting foundations for any universal moral or ethical code, where nothing fixed or certain can be relied on any more. For nurses, this is not completely grounds for pessimism. It is left open for individuals to decide moral dilemmas, and these boil down to contemplation of the manifest needs and vulnerabilities of 'others'. To some extent, notable examples of nurse whistleblowing demonstrate that nurses can live up to progressive ethics and advocate for vulnerable persons, in the face of threats to their own welfare (Jackson 2008). If nurses can be supported to maximise their agency and autonomy, in the face of liquidity, then encounters that exemplify care and compassion for the 'other' may accumulate to be not so far removed from the sort of ideal cultures which are thought to be lacking right now. Yet, for all of his implicit pessimism for the future of work under global capitalism, Bauman (2012: 167) notes the sense that workers' solidarity embodies:

The inchoate and as yet inarticulate (but inborn and in the long run overwhelming) desire for a 'good society' which would make flesh the universal principles of justice.

Emancipatory visions for the future, however, may remain somewhat utopian at present, and perhaps, for Bauman, are delusionary.

It is perhaps not so surprising given the fear, impermanence and uncertainty of the modern liquid state in nursing that at least some nurses lose sight of the fellow human lives in which they are involved. In such a system patients become objects to be processed and despatched. Nurses have to be mindful that if they do not process patients as required by the system the competition will move in and take over the process (even if this would in reality be unlikely, or even impossible, the threat is ever present). In any case the nurse will move on in their career, be reorganised or relocated, the likelihood that they will have to face the patient again on readmission or explain care to their family is diminished. Liquid nursing for nurses, a nasty competitive world for patients: a sub human purgatory. 


\section{References}

Bauman Z (2000) Liquid modernity. Polity Press, Cambridge. [2 ${ }^{\text {nd }}$ edition 2012]

Briskin L (2011) The militancy of nurses and union renewal. Transfer: European Review of Labour and Research 17, 484-499.

Department of Health (2006) Modernising Nursing Careers: setting the direction.

Department of Health, London.

Hochschild A (1983) The Managed Heart. University of California Press, Berkeley California .

Her Majesties Government (2013) The Mid Staffordshire NHS Foundation Trust Public Inquiry. Available at: http://www.midstaffspublicinquiry.com/report (Accessed $17^{\text {th }}$ June 2013)

Jackson D (2008) Editorial: What becomes of the whistleblowers? Journal of Clinical Nursing $17,1261-1262$

McKeown M, Spandler H \& Cresswell M (in press) Deeply engaged relationships? Trade Unionism and the Organized Left's Alliance Building with Psychiatric Survivors in the UK. In Burstow B, Diamond SL \& LeFrancois BA (eds) Psychiatry Disrupted: Theorizing Resistance and Crafting the (R)evolution. McGill/Queen's University Press, Montreal \& Kingston.

Randall D \& Hill A (2012) Consulting children and young people on what makes a good nurse. Nursing Children and Young People 24, 14-19.

Reich A (2012) With God on our side: the struggle for workers' rights in a Catholic hospital. ILR Press, Ithaca, New York.

Theodosius C (2008) Emotional labour in healthcare: the unmanaged heart of nursing. Routledge, Abingdon. 